\title{
Remote Assistive Elevator Control Device
}

\author{
Janak Dave, Thomas G. Boronkay, James Henize \\ University of Cincinnati
}

\begin{abstract}
The Mechanical Engineering Technology (MET) Department at the University of Cincinnati's College of Applied Science requires a "Design, Build \& Test" Capstone design project for students working toward the baccalaureate degree. Most of these are completed by individual students. Local non-profit organizations that offer community service provide some of the projects. By working with these organizations, the MET Department has identified problems students can solve. Improving the quality of life for the elderly and people wit physical disabilities is the current focus for these projects.
\end{abstract}

A local rehabilitation center, Beechwood Home, approached the MET department to find a solution to the following problem. Many disabled people who have the mobility in their arms and hands to operate powered wheelchairs do not have sufficient strength or the ability to extend their arms to operate the buttons of standard elevator control panels. This is due to their physical limitations and the common placement of control panels in elevator cars. The size and mobility of the powered wheelchairs prevents these users from being able to maneuver close enough to the control panels to reach the buttons. These patients cannot use the elevators in their building without the assistance of a health care provider.

This paper describes a project by James Henize that helped solve this problem from concept to the final working prototype. The practical solution was a remote assistive device, mounted on the wheelchair, to be used by patients with little effort and without help of a health care provider.

\section{Introduction}

Diseases such as cerebral palsy, multiple sclerosis, Parkinson's disease, arthritis, and stroke affect millions of Americans and, in many cases, result in permanent confinement to wheelchairs $[1,2]$. While the electric powered wheelchair improves the lives of thousands of disabled people by giving them some degree of personal mobility, their inability to operate elevator buttons can limit that mobility to a single floor of multi-story buildings. No practical, inexpensive device exists to allow these people to transfer limited hand motion to the proper location to activate elevator call and floor selection buttons. 
A device allowing patients to independently operate elevators would increase their sense of independence. Anything that helps in this area is a major improvement to the quality of life for them.

\section{Design}

There is a wide range of capabilities and physical limitations among patients confined to wheelchairs. The targeted customers for this project are those disabled people who have the mobility in their hands and arms to operate powered wheelchairs but lack sufficient strength or reach to extend their arms to operate elevator control buttons. Additionally, a wide variety of elevator configurations exist, since many buildings currently in use were constructed prior to the 1992 ADA (Americans with Disability Act) legislation on accessibility for the handicapped. The location of elevator call buttons and control panels varies widely in such buildings. While the design concept resulting from this project may be applied to a wide variety of health care facilities, the prototype built for this project was constructed specifically for the elevator system of Beechwood Home in Cincinnati, Ohio.

\section{Product Specifications}

A survey form was developed and distributed to the healthcare professionals and targeted patients at the Beechwood Home. Questions focused on frequency of elevator use, range of user motion, mounting location of the remote control, and cost, among others. Personal interviews were also conducted at the Beechwood facility $[3,4]$. The results from surveys were used to determine user (patient) needs. The following design requirements for the prototype were developed based on personal observations of James Henize, the student, who completed the project, interviews and survey result:

- Allow operation of existing elevator controls from a wheelchair

- Remain as compact as possible

- Require no precise aiming of the control device

- Allow simple mounting of control device

- Allow operation by the identified customers and normal users

The next two requirements were incorporated to allow the use of the existing elevator buttons and controls.

- Apply a minimum of $1 \mathrm{lb}$ and a maximum of $4 \mathrm{lb}$ force to existing buttons

- Displace existing buttons by at least .125 inch and no more than .200 inch

\section{Detail Design}

The prototype is subdivided into two major subassemblies: Housing Assemblies and Control System. Each component of the subassemblies was selected from different alternatives using the Pugh selection method [5]. This method compares each alternative to a datum and suggests the best alternative. The alternatives considered for the Housing 
Assembly were: Push Button Infrared, Rocker Infrared, Push Button Radio Frequency and Rocker Radio Frequency. Rocker IR (Infrared) was used as a datum. Similarly, Solenoid and Servo were the two alternatives for the Control System.

\section{Control System}

The design criteria used for control system selection were:

- Transmitter size

- Directional sensitivity

- Manufacturing cost

- Ease of operation

- Component availability

An infrared remote with push button control was selected because of its superiority over an RF (Radio Frequency) remote. The selected system operates on 12v DC, $100 \mathrm{~mA}$ input power. This system provides momentary relay-controlled output so the solenoid is actuated only while the remote transmitter button is depressed. Only one relay can be actuated at a time, limiting the forces on the system to the output of a single solenoid. While only two output relays are required for this prototype, the selected system has four relays per receiver. This is not a design requirement but simply the result of selecting from a limited number of available systems. The selected receiver/relay board is quite compact, being only 1.9 " x 2.95 " by .75 ". The output relays are capable of carrying a 1 amp load, which is more than sufficient for the $.5 \mathrm{amp}$ load of the system solenoids. Each receiver is furnished with a transmitter and for this application, multiple receivers are programmed to operate using a single set of transmitter codes. This allows a single transmitter to operate both the hall call and in-car control systems. Additional transmitters can be added using the same codes to allow an unlimited number of users.

\section{Housing Assemblies}

The Housing Assemblies (Figure 1) are designed to support and align the extension button assemblies and to provide the required space for mounting the remote control receiver and power supply systems. Each Housing Assembly is constructed of .250 inch clear acrylic sheet stock, allowing the existing illuminated control buttons to be visible to the system user and providing the required rigidity. The Housing Assembly is mounted directly over the existing elevator control buttons. It supports the outer end of each extension button at the switch plate. The switch plate was added to the design to allow for replacement of extension buttons without removing the complete assembly from the wall. 


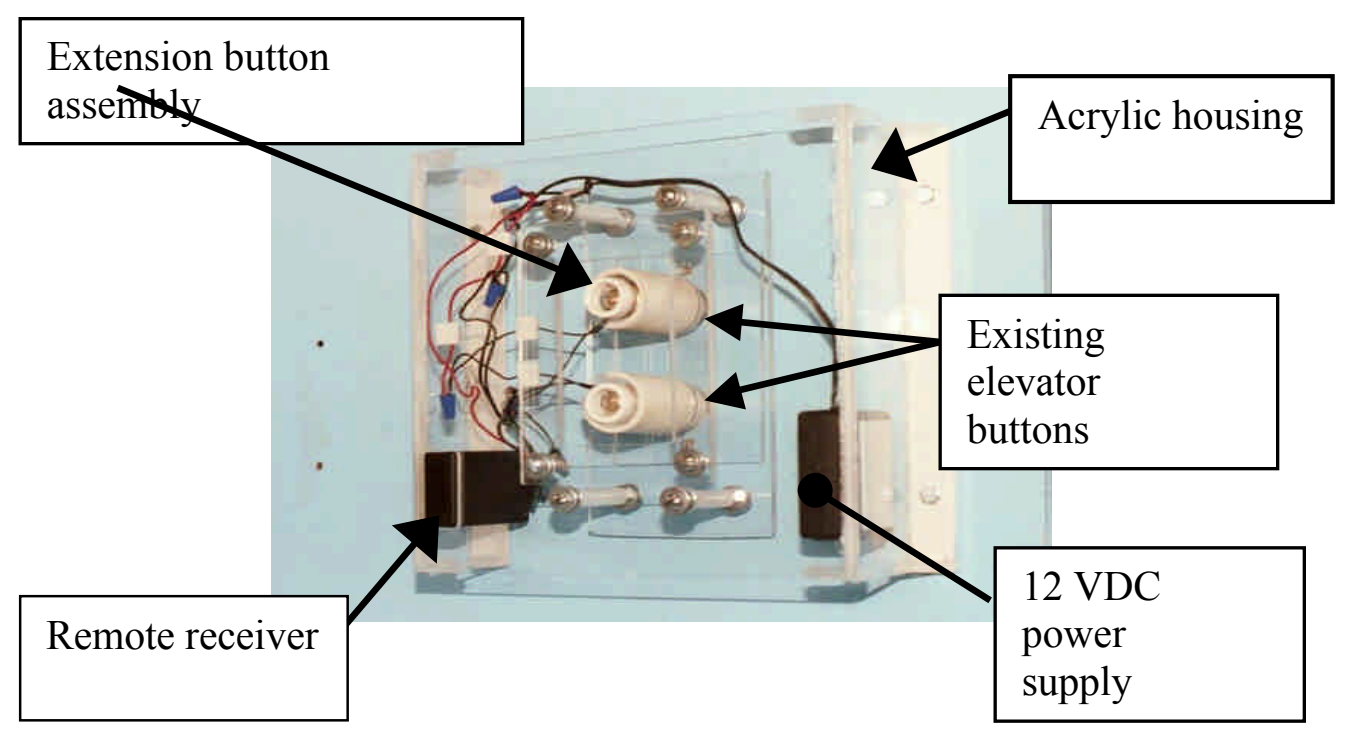

Figure 1 Wall Mounted Assembly

\section{Extension Button Assembly}

The extension button assembly is designed to provide sufficient space for mounting the electric solenoid and to provide for normal manual actuation of the existing elevator control button (Figure 2). Design of this assembly was based on the force and displacement required to actuate the existing elevator buttons and on the need to provide for both remote and normal operation. The extension button assembly is a hollow cylinder with support journals at the inner and outer ends. This cylinder is positioned in the wall- mounted assembly with the inner end resting against the existing elevator button. Normal operation is made possible by the transfer of force and displacement through the cylinder to the existing button. The force needed for normal manual elevator operation will be unaffected. All of the extension buttons for both the hall call and floor selection assemblies are identical and one extension button assembly is required for each existing button to be operated.

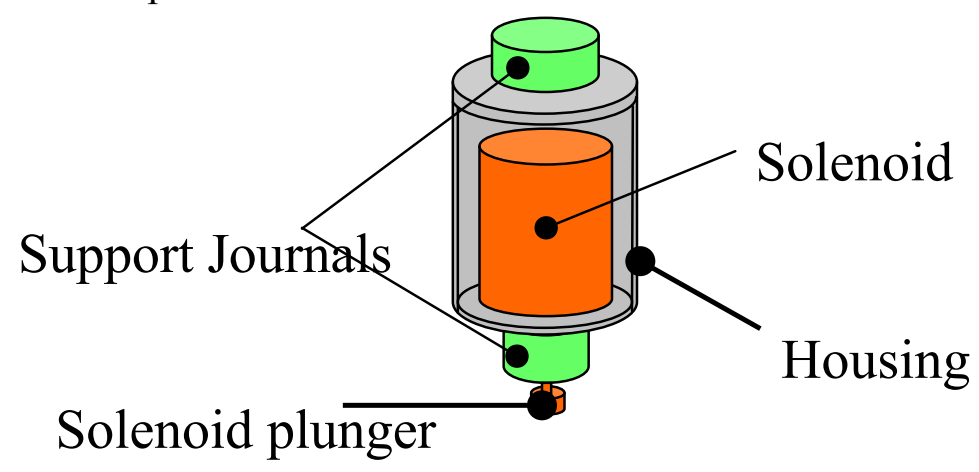

Figure 2 Extension Button Assembly 


\section{Solenoid}

Using typical continuous duty solenoid force curves for $12 \mathrm{v}$ DC, a 1 inch diameter by 2 inch long solenoid was selected for meeting force and stroke requirements (Figure3). The force curve is relatively flat at the higher stroke ranges and climbs sharply as the stroke nears 0 . This selection was made to avoid the possibility of solenoid damage and a possible fire hazard in the event the user depresses the remote transmitter button and fails to release it in a short time. As illustrated in the force curve (Figure 3), the selected solenoid is capable of applying $10.3 \mathrm{lbs}$ of force in the sealed position.

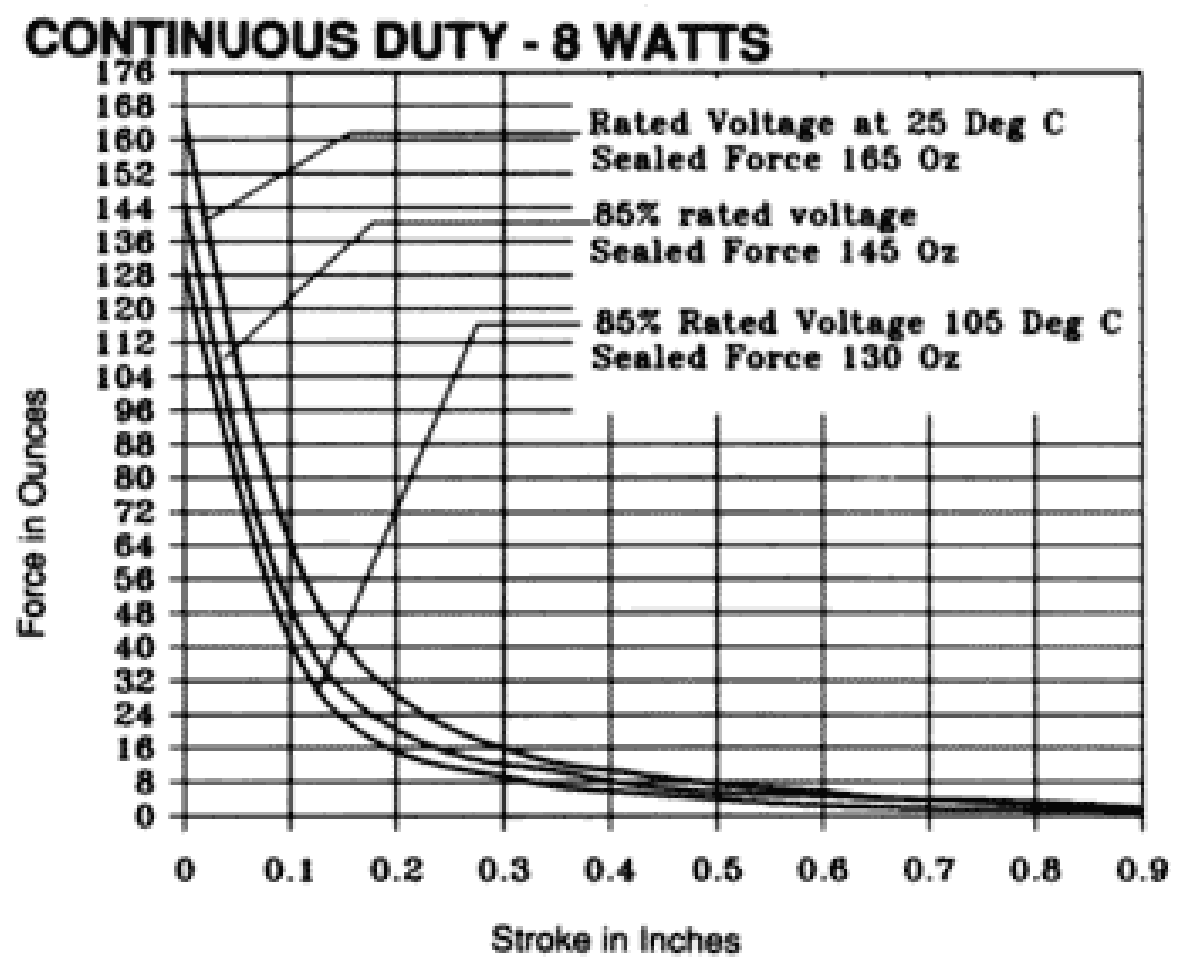

Copyright 1999 Pontiac Coil, Inc.

Figure 3 Typical Solenoid Force Curve

\section{Prototype System Operation}

The prototype allows simple remote and normal operation of existing elevator control buttons. For remote operation, the user presses a button on a wheelchair mounted remote control transmitter to select the desired function. The remote receiver senses the infrared signal and activates the corresponding relay of the receiver/relay board. When the relay contacts close, the solenoid circuit is completed and the solenoid plunger extends, providing the required force and stroke to depress the existing elevator button. The indicator light of the existing button provides feedback to the user, indicating when the correct button has been selected. Normal operation is possible simply by pressing the outer end of the extension button assembly which extends beyond the outer surface of the housing assembly. Each extension button is marked exactly as the existing buttons of the elevator control panel. 
Users are able to operate both the hall call buttons and the in car floor selection buttons using a single remote transmitter. The transmitter for the prototype has buttons for up, down, floor 1 , and floor 2 selections. As additional floors or functions are added, the number of buttons on the remote control transmitter will be increased.

\section{Fabrication}

All fabrication was completed using standard hand tools. Housing panels were cut using handsaws and sanded to final dimensions. Large diameter holes for extension button support journals were cut, and enlarged to final design dimensions using abrasive reamers. Final Assembly of the remote receiver and power supply the individual housings was accomplished using two-sided tape. The wiring diagram for the prototype is shown in Figure 4. Each housing assembly contains a single $110 \mathrm{v}$ AC to $12 \mathrm{v}$ DC converter to supply power for both the infrared remote receiver and the extension button solenoids. This allows for easy connection of the assembly to a standard electrical outlet, or with simple modifications, to existing facility wiring for a production system.

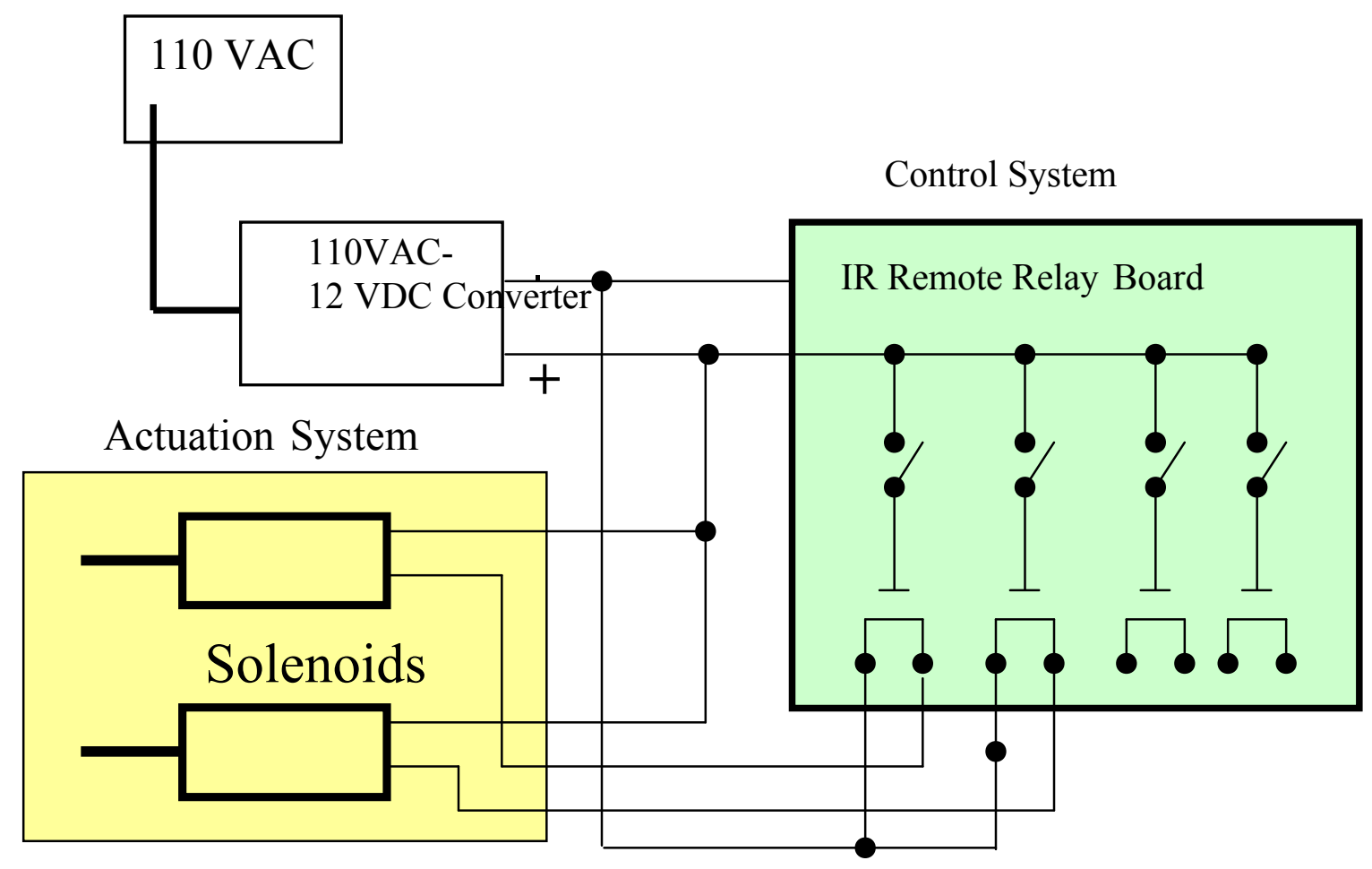

Figure 4 Wiring Diagram

\section{Testing}

When fabrication was complete, the housings were tested for joint strength. Due to the low forces in the overall system applied by the solenoid plungers against the existing elevator control buttons, these joints were only required to carry a maximum load of $4 \mathrm{lb}$. This testing was performed by securing the housing mounting flanges to a workbench 
and applying a force to pull the housing away from the workbench. A force of $20 \mathrm{lbs}$ was applied with no damage to the housing or separation of joints. This test indicates that the housings will withstand a load of at least 5 times what they will experience in actual operation. Prior to final assembly, each solenoid was tested for proper output force and displacement. Based on this testing, each solenoid plunger length was adjusted to provide the required force and stroke. The infrared control system was tested prior to installation into the assembly to assure that it operated over the required range and to prove that precise aiming of the transmitter was not required. This testing revealed that at distances of up to 8 feet, the transmitter could be positioned at any angle up to 90 degrees from the receiver and still function properly. At distances of from 8 to 15 feet, the transmitter must be aimed within an arc of 30 degrees in any direction from the receiver. At distances exceeding 15 feet, the transmitter must be aimed almost directly at the receiver, with the need for precise aiming increasing as the distance between transmitter and receiver increases. This testing proves that within the specified range, the control system does not require precise aiming to function properly. Testing of the completed assemblies was performed for proper remote and normal operation. As a result of this testing, shimming was added to assure reliable system operation.

Three Beechwood Home residents tested the device. Each used the remote control to successfully call both up and down elevators and to operate the elevator between the first and second floors of the Beechwood facility without affecting the normal elevator operation. All of the residents participating in this test were impressed with the ease with which they were able to operate the elevator. During this test, the prototype performed as expected and met all design requirements.

\section{Production Considerations}

The cost of materials and components for the prototype was $\$ 260.00$. Major costs included the remote control system at $\$ 75$ each, housing material $\$ 35$ and solenoids at $\$ 16$ each. The estimated cost per unit to produce these systems does not decrease significantly with high volume production. Due to the variation in control panel design between different elevator models and installations, housings would be custom-built for each installation. The most that can be expected is a volume discount of $20 \%$ on purchased components. The estimated cost for a four-story building is $\$ 1200$.

\section{Conclusion}

Final testing demonstrated that the prototype met all identified customer and design requirements. Users can actuate elevator controls without extending their arms. They can operate the hall call buttons from almost any position in the lobby and can operate the floor selection buttons without maneuvering their wheelchairs to any particular position in the car. The compact size of the remote control unit allows the system to function without interfering with normal use of the wheelchair by the patient or by health care providers.

"Proceedings of the 2003 American Society for Engineering Education Annual Conference \& Exposition" Copyright (C2003, American Society for Engineering 
Demonstration of the prototype by residents of Beechwood Home proved that precise aiming of the remote control was not required. Through the use of a universal mount, patients can keep the remote control handy in whatever position they find most convenient for their particular disabilities and wheelchair designs. While the prototype was custom made for the Beechwood Home facility, the design concept can be applied for use on virtually any existing elevator control panel at a savings of $80 \%$ as compared to currently available systems. This device will provide increased personal freedom, offering a significant improvement in the quality of life for its users.

Oral and written communication, project management, bringing an idea to a prototype, as well as other outcomes are some of the learning objectives that are satisfied by all MET students completing their senior design project. In addition to satisfying these learning objectives, the student, James Henize, had to solve problems associated with working on a quality of life project and familiarization with diverse testing environment.

These type of projects foster good relationships between the university and local community organizations.

\section{Recommendations}

A number of recommendations have been identified for future improvements, based on testing of the prototype:

1. Using smoked acrylic for housing in place of clear acrylic to hide dirt, fingerprints, and internal system components.

2. Increasing the size, spacing and marking of the control buttons on the remote control to minimize floor selection errors by the patients.

3. Using a molded plastic housing for high volume production could result in reduced manufacturing time and cost. If the housings could be standardized and molded rather than assembled from individually cut panels, approximately half the assembly time would be eliminated.

4. The use of a learning remote control could allow a much wider range of users to operate this system. Systems are currently available to convert a variety of user inputs to infrared signals. If the remote receiver used in the wall mounted unit could be taught to recognize these infrared signals, users could operate the elevator buttons using such input as voice control, eye blinks, head nods, or whatever other input they were using to operate their wheelchairs. While this improvement might have a significant impact on product cost, the obvious benefits make this an exciting possibility.

"Proceedings of the 2003 American Society for Engineering Education Annual Conference \& Exposition" Copyright (C2003, American Society for Engineering 


\section{References}

1. New York Online Access to Health (NOAH)

On-line information inquiries, May 2002

2. The National Spinal Cord Injury Statistical Center (NSCISC),

Board of Trustees, University of Alabama, 2001.

On-line information inquiries, August 2001 through May 2002

3. K. Barker, Director of Physical Therapy, Beechwood Home, Cincinnati, Ohio,

Personal Discussions, August and November, 2001.

4. R. Loftspring, Physical Therapist, Beechwood Home, Cincinnati, Ohio,

Personal Discussions, November, 2001.

5. Dieter, George E., Engineering Design, McGraw Hill, 2000.

6. International Senior Capstone Design Initiative, Boronkay, Thomas; Dave, Janak; Al-

Ubaidi, Muthar, Proceeding of ASEE 2002 Annual Conference, Montreal Canada.

Janak Dave PhD, PE is a Professor in the department of Mechanical Engineering Technology at the University of Cincinnati. He obtained his MS and PhD in Mechanical Engineering from the University of Missouri at Rolla. He has presented papers at ASEE Annual Conferences, ASME International Congress, and several International conferences and conducted CAD/CAM/CAE workshops nationally and internationally. He has held various positions in EDG and DEED divisions of ASEE, and local and national committees of ASME.

Thomas G. Boronkay, PhD, PE is a Professor in the department of Mechanical Engineering Technology at the University of Cincinnati. He received his $\mathrm{PhD}$ from the University of Cincinnati. He has presented papers at ASEE Annual Conferences, ASME International Congress, and several international conferences and conducted $\mathrm{CAD} / \mathrm{CAM} / \mathrm{CAE}$ workshops nationally and internationally. He has also served in various capacities on the DEED, EDG and International Divisions' executive committees.

James Henize received his BS in Mechanical Engineering Technology from the University of Cincinnati, College of Applied Science in 2002. He has been employed by GE Aircraft Engines since 1986, working as an assembly supervisor, process control engineering specialist, and assembly configuration control specialist.

"Proceedings of the 2003 American Society for Engineering Education Annual Conference \& Exposition" Copyright (C2003, American Society for Engineering 